\title{
5. EL DERECHO DE ANTENA Y LAS CAMPAÑAS
} ELECTORALES

\author{
E. GARCIA LLOVET \\ Departamento de Derecho Administrativo \\ Facultad de Ciencias de la Información \\ Universidad Complutense
}




\section{SUMARIO}

1.-NATURALEZA Y SEDE CONSTITUCIONAL DEL DERECHO DE ANTENA EN PERIODOS ELECTORALES. II.-DERECHO DE ANTENA Y CAMPAÑAS ELECTORALES. III.-EL MARCO CONSTITUCIONAL DEL DERECHO DE ANTENA EN PERIODOS ELECTORALES. IV.-EL DERECHO DE ANTENA EN LA LEGISLACIÓN ELECTORAL (1977-1982). V.-LA LEY ORGANICA DE REGIMEN ELECTORAL GENERAL.-A) Campaña electoral: concepto y régimen jurídico. B) El acceso de los partidos a los medios de titularidad pública y la disciplina de la propaganda en los medios de titularidad privada. C) La neutralidad informativa de los medios de titularidad pública. D) Los órganos competentes. VI.-LAS ELECCIONES DE 22 DE JUNIO DE 1986.-A) Comisión de Radio y Televisión. B) La distribución de los espacios gratuitos de propaganda electoral. C) Pluralismo y mentalidad informativa de los medios de comunicación de titularidad pública.-CONCLUSIONES. 
Revista de Derecho Político, núm. 25, 1987, págs. 151-181

\title{
5. EL DERECHO DE ANTENA Y LAS CAMPAÑAS ELECTORALES
}

\author{
POR \\ E. GARCIA LLOVET \\ Departamento de Derecho Administrativo \\ Facultad de Ciencias de la Información \\ Universidad Complutense
}

Los estudios sobre propaganda electoral aunque abundantes desde una perspectiva sociológica o política, en una dimensión estrictamente jurídica, han merecido una limitada atención de nuestra doctrina.

La ausencia de una normativa electoral general, hasta fechas recientes, podría explicar esta actitud tan sólo en parte, pues otros aspectos de nuestro derecho electoral habían merecido ya la atención de la doctrina con anterioridad a la publicación de la Ley 5/1985 de 19 de junio.

El estudio que sigue pretende, dentro de los límites de su extensión, analizar algunos de los aspectos más relevantes de la disciplina juridica de la propaganda en procesos electorales.

Se dedica especial atención a la regulación del derecho de antena en períodos electorales, por una razón: la novedad de esta institución en nuestro derecho.

\section{NATURALEZA Y SEDE CONSTITUCIONAL DEL DERECHO DE ANTENA EN PERIODOS ELECTORALES}

El derecho de antena o derecho de acceso, es uno de los últimos derechos fundamentales incorporados al amplio bloque de derechos que agrupamos bajo la denominación de libertades de la comunicación social. 
El acceso de los grupos sociales a los medios de comunicación de titularidad pública pretende garantizar, complementariamente a las propias estructuras del servicio, la consecución de los mayores niveles de pluralismo posible.

El derecho de antena en períodos normales y en períodos electorales presenta perfiles sustancialmente diferentes.

Lo característico del derecho de antena es la pretensión de articular el pluralismo inmediato en el medio de comunicación.

Las organizaciones que acceden como portavoces de grupos sociales son, así, expresión de ese pluralismo, a la vez que instrumento para impulsarlo.

El derecho de antena se nos presenta como una garantía del pluralismo en el servicio público.

La situación en el derecho de antena en períodos electorales es sustancialmente distinta. La determinación de los sujetos es con regularidad más accesible: los sujetos llamados al acceso, los titulares del derecho, son fundamentalmente los partidos políticos y coaliciones, aunque posteriormente analizaremos esta cuestión.

Pero además, y esto es especialmente importante, la pretensión de estos espacios y tiempos de emisión a disposición de las distintas fuerzas políticas no es ser vehículo para un pluralismo interno del medio de comunicación, su funcionalidad inmediata y directa es la oferta pública de un pluralismo preexistente, individualizado en los distintos grupos politicos, siendo un instrumento más de la propaganda política de estos grupos para la captación de electores. Este carácter instrumental no tiene, como veremos, una dimensión teleológica, pues estos espacios están al servicio de una correcta formación de la opinión pública.

El derecho de antena ha sido definido por ZACCARIA como una sindemnización normativa frente a la expropiación del derecho de libertad de expresión” '.

La definición del derecho de antena en estos términos -que ha sido aceptada en su concepción original por la doctrina italiana, es susceptible de explicar en buena medida el derecho de antena en gene$\mathrm{ral}^{2}$ - tiene como presupuesto material y formal el monopolio de los medios de comunicación por el Estado, no es, sin embargo, adecuada para explicar el derecho de antena en períodos electorales.

Las consecuencias de esta tesis son importantes. En primer lugar

1 R. ZaCCARIA: Radiotelevisione e costituzione. Milano, 1977.

2 No quiere esto decir que aceptamos la tesis sostenida, si bien la fuerza gráfica de esta definición resulta altamente explicativa siempre que entendamos que la "expropiación" se ha realizado sobre el conjunto de la sociedad y no sobre unos. 
una concepción «indemnizatoria» exigiría una previa «expropiación» del medio no siendo justificable una disciplina del acceso de los grupos políticos en períodos electorales a medios de comunicación de titularidad privada. Tal disciplina no supone necesariamente el reconocimiento de un derecho de acceso; siendo, por ejemplo, aceptable como principio primario en la regulación de la propaganda, la preservación de la regla del equal time consagrada en la jurisprudencia norteamericana desde la Sentencia Red Lion Broadcasting Co. vs. FCC, y recogida en la jurisprudencia constitucional italiana ya en la Sentencia 48/1964.

La naturaleza de estas obligaciones, incluso sobre empresas privadas gestoras de servicios de comunicación social, nos orienta hacia la funcionalidad de estos derechos, en la línea que hemos apuntado, ésta no es otra que la consecución de una confrontación paritaria, como nos recuerda CHIOLA. "Cualquier otro criterio en la distribución de los espacios de la propaganda electoral radiotelevisiva acabaría por disminuir la libertad del proceso formativo de la voluntad general» ${ }^{3}$. actividad.

Lo que nos conduce a la cuestión de la sede constitucional de esta

Esta sede puede buscarse bien en las libertades que amparan la comunicación pública (libertades de información y expresión de opinión, derecho a la información) ${ }^{4}$, bien en los derechos conectados directa e indirectamente con la participación política.

La ubicación en una u otra sede supondría, en principio, otorgarles naturaleza muy distinta, de acuerdo con las clasificaciones al uso.

Si admitimos su ubicación en las libertades de la comunicación social, nos encontrariamos en presencia de un derecho de autonomía, siendo el medio de comunicación un instrumento al servicio del partido político o coalición, pero si, por el contrario, estimamos como más solvente su relación con los derechos de participación, su estructura respondería a esta segunda naturaleza, siendo un instrumento al servicio de una información del ciudadano (una información sobre opiniones y programas) y no un mero instrumento de los partidos (pese a que sean éstos los que difunden sus ofertas electorales).

Permítasenos adelantar que no sólo rechazamos el contenido de esta polémica sino que cuestionamos, incluso, sus mismas bases.

Empieza a ser admitido por una parte de la doctrina que la clasificación de los derechos fundamentales de acuerdo con su naturaleza pasa por una distinción entre derechos de autonomía y participación y derechos económicos, sociales y culturales. Se supera así la tradicional divi-

3 ChIOLA «La disciplina delle trasmisioni radiotelevisivi preelettorali» en // Diritto delle comunicazioni di Masa, Padua 1985, pág. 82.

4 Encontrar la conexión nos llevaria a la libertad de expresión, de opinión. 
sión entre derechos de autonomía y derechos de participación. Esto es especialmente exacto respecto de las libertades de la comunicación social. La decisiva importancia que para el desarrollo institucional de una sociedad democrática tienen, transforma la naturaleza de estos derechos, superando sin eliminar una dimensión subjetiva, fundada en el principio de la autonomía de la voluntad y el interés particular como fin último, para dotarles de una dimensión social y funcional. El conjunto de los ciudadanos son asi beneficiarios reflejos de la actividad del individuo y titulares de nuevos derechos producto directo de este proceso.

Una solución en esta linea nos llevaria a una determinación sincrética de la sede constitucional del derecho de antena en períodos electorales.

Esta tendría su sede en los derechos referentes a la participación en los procesos electorales en la doble función activa y pasiva, pero en conexión con los principios que rigen las libertades de la comunicación social; en último término esta conexión obraría en igual sentido, pues el fin de las libertades de comunicación no es otro que el servicio al pluralismo en el ejercicio de las libertades y el funcionamiento de las instituciones del Estado.

Así lo ha afirmado nuestro Tribunal Constitucional en la STC 6/1981 de 16 de marzo:

«El articulo 20 en sus distintos apartados garantiza el mantenimiento de una comunicación pública libre, sin la cual quedarían vaciados de contenido real otros derechos que la Constitución consagra reducidos a formas hueras las instituciones representativas y absolutamente falseado el principio de legitimidad que enuncia el artículo 1, apartado 2 de la Constitución y que es la base de toda nuestra ordenación juridico-política.»

El fondo de la polémica no es otro que la tensión entre una estructura individualista de la que se ha pretendido dotar, en coherencia con los presupuestos ideológicos que fundamentan las primeras declaraciones de derechos, a las libertades de comunicación social.

Una comprensión de las libertades de comunicación como libertades de acción social o colectiva resuelve el conflicto ${ }^{5}$.

El derecho de antena en razón de ello, se conformaría siempre como una libertad colectiva, definiéndose de este modo su ámbito y las condiciones de su ejercicio.

El derecho de antena en períodos electorales será, así, una garan-

5 Sobre las libertades de la comunicación como libertades colectivas vid MORANGE: Libertes publiques. Paris, 1985. 
tía de un interés de los grupos políticos que tendrá como beneficiario a todo el cuerpo electoral.

\section{DERECHO DE ANTENA Y CAMPAÑAS ELECTORALES}

El marco general donde se desenvuelve este derecho de antena es el de la propaganda política en períodos electorales.

La oferta al elector de un programa electoral (programa de gobierno aunque en ocasiones «programa de oposición») así como de los candidatos no se vehicula tan sólo a través de los medios de comunicación social. La difusión de la oferta electoral, programas y candidatos, es onerosa. El coste económico de las campañas electorales lleva a LOEWENSTEIN a afirmar parafraseando a Montecuccoli «los tres elementos imprescindibles en una campaña electoral son: dinero, derecho y otra vez dinero» 6 .

Los problemas de financiación se han convertido en factor determinante de las estrategias de los partidos políticos y coaliciones, considerándose en muchas ocasiones como un elemento determinante de los resultados electorales. "Hoy ha desaparecido toda duda de que la desigualdad de los partidos y los candidatos en los medios económicos de que disponen para la campaña y consiguientemente la desigualdad en el uso de los medios de comunicación, tiene una importancia decisiva para el resultado de una decisión" 7.

Por ello, parece necesario que la búsqueda de una igualdad de oportunidades de todos los candidatos, de todos los programas, no se reduzca a poner a disposición de los distintos grupos una serie de espacios y tiempos con el fin de garantizar unos mínimos de publicidad (de oportunidad de conocimiento) de esas ofertas.

Las técnicas utilizadas para paliar esa situación de desequilibrio son variadas, y van a repercutir directamente en las campañas electorales ${ }^{8}$; destaquemos tres de ellas:

6 LoEWENSTEIN: Teoría de la Constitución. Barcelona. 1982, pág. 343.

7 Idem. Ob. cit., pág. 343. El mecanismo de financiación no funciona automáticamente, sin embargo. Hemos tenido oportunidad de comprobarlo en estas últimas elecciones generales donde un partido con unos medios de financiación y un acceso mayor a los medios de comunicación social como el PRD, fue derrotado por un partido como el CDS en una situación de inferioridad financiera, en la pugna que sostienen por aglutinar un nuevo espacio de centro reformista.

8 Vid. LOPEZ GuERRA: El proceso electoral. Madrid, 1977, págs. 117 y ss. Volumen dirigido por J. DE ESTEBAN. 
a) La limitación de los gastos que puede realizar en una campaña cualquier partido o coalición, pretende, ante todo, evitar que una formación política con unas estructuras financieras muy superiores al resto de los grupos contendientes, anulara en la práctica las posibilidades de propaganda de sus contrincantes, en este sentido obraría como una técnica de defensa de la competencia ${ }^{9}$.

b) Financiación limitada y a posteriori de las campañas electorales de aquellos partidos que han obtenido un respaldo electoral en proporción a éste ${ }^{10}$.

c) Subvenciones indirectas, exenciones o reducciones de determinadas tarifas de servicios (así el régimen de franquicias postales).

Junto a estas medidas tendentes a garantizar un mínimo de igualdad material de oportunidades, un minimum de igualdad formal de oportunidades exige una neutralidad tanto de las organizaciones públicas y privadas de gestión de servicios de comunicación social en el tratamiento informativo de las campañas, asi como la no discriminación en la disponibilidad de espacios de publicidad pagada (normalmente sólo posible en las últimas).

\section{EL MARCO CONSTITUCIONAL DEL DERECHO DE ANTENA EN PERIODOS ELECTORALES}

La Constitución de la República Portuguesa de 2 de abril de 1976 fue la primera en recoger el derecho de antena:

"Los partidos políticos y las organizaciones sindicales y profesionales tendrán derecho a períodos de emisión en la radio y la televisión de acuerdo con su representatividad y según los criterios que se especifique en la ley" (Ley Constitucional 1/1982) (Artículo 40.1).

9 El control sobre el origen de los ingresos, asi como una limitación en cuanto a la concentración de las fuentes particulares de financiación de las partidas, pretende garantizar una independencia de éstas.

${ }_{10}$ La liquidación de las cargas financieras asumidas anteriormente dependen en la mayoría de los casos de esta financiación estatal. 


\section{E igualmente su regulación en periodos electorales:}

«En época de elecciones los partidos políticos concurrentes tendrán derecho a periodos de emisión regulares y equitativos" (Artículo 40.2) ${ }^{11}$.

No existe en nuestro texto constitucional, por el contrario, una referencia expresa al derecho de antena en periodos electorales, mencionándose tan sólo el acceso a los medios de comunicación de titularidad pública de los grupos políticos y sociales significativos (Artículo 20.3).

Para identificar la disciplina constitucional del derecho de antena en períodos electorales, hemos de realizar un breve análisis del artículo 23 , en relación con la propaganda.

Una regulación de la propaganda en periodos electorales que intenta proporcionar una igualdad de oportunidades de las distintas formaciones, garantiza simultáneamente los derechos electorales activos y pasivos reconocidos en el artículo 23 de la C.E.

Respecto del derecho de sufragio activo, la participación mediante "representantes libremente elegidos en elecciones periódicas por sufragio universal", exige definir lo que entendemos por una elección libre. Esta no es sólo aquella en la que no existe coacción sobre el ciudadano, entendemos que sólo se puede reputar como libre una elección donde se le proporciona al ciudadano el pleno conocimiento de los distintos grupos políticos. Los poderes públicos no pueden por ello limitarse a garantizar la ausencia de coacciones, sino que deben, además, realizar una actividad pública que garantice ese conocimiento.

Respecto del derecho de sufragio pasivo, una concurrencia de los candidatos en igualdad de condiciones sería un requisito para el correcto funcionamiento del proceso electoral, pero además, supondría una concreción del principio de igualdad recogida en el artículo 14 del texto constitucional, en conexión con el 9.2.

"El derecho a la igualdad en el acceso a cargos y funciones públicas tiene también efectos reflejos sobre la situación de las personas jurídicas. Así, por ejemplo, el artículo 23.2 que reconoce el derecho de los ciudadanos a presentarse en condiciones de igualdad, conlleva el derecho de los partidos políticos a concurrir en

11 La Constitución de la República Portuguesa de 1976 incorpora una regulación detallada de las libertades de la comunicación social, dedicándole cuatro extensos artículos. La amplitud del texto constitucional con el articulado más extenso de los existentes en la actualidad, puede jurtificar la prolija ordenación constitucional del sector. El texto es el aprobado por la Ley Constitucional 1/1982, de 30 de septiembre. 
los procesos electorales en las mismas condiciones sin discriminación posiblen 12 .

La interdicción de la discriminación tiene como objeto inmediato el acceso a los medios de comunicación de titularidad pública, pero puede fundamentar también una adecudada disciplina de la propaganda electoral en medios de titularidad privada.

El libre juego del mercado y la concentración de los medios de comunicación puede alterar sustancialmente su neutralidad en los procesos electorales. "La libertad política se encuentra en una encrucijada. Está puesta en peligro por la concentración de poder que forma la opinión pública en las manos de algunos pocos que están en situación de pagar los gastos necesarios. Lo mismo que en el campo de la economía, el máximo de libertad política no es en absoluto idéntico con el grado óptimo de igualdad políticam ${ }^{13}$.

Un segundo aspecto a considerar en el estudio del marco constitucional de la propaganda electoral es el de los sujetos legitimados para la realización de actos o la difusión de mensajes de esta naturaleza.

El pluralismo no se reduce en una sociedad democrática avanzada tal como lo define nuestro texto constitucional, pero lo cierto es que en los procesos electorales una sociedad de naturaleza plural (social, cultural, lingüística) cristaliza su heterogeneidad en un pluralismo político.

Los partidos políticos son la expresión primaria de este pluralismo, tanto en nuestro ordenamiento como en el conjunto de los sistemas pluripartidistas.

Marginadas las fórmulas de participación directa, los procesos electorales son los cauces de la participación sobre la que se articula todo sistema democrático, y los partidos los medios que hacen posible esta democracia representativa.

«Sólo los partidos pueden cumplir la función de transformar las orientaciones y actitudes políticas generales sentidas por ciertos sectores de la sociedad en programaciones de acción política nacional y convertir las necesidades expresas o latentes y los deseos más o menos vagos y difusos de conjuntos de la población, en pretensiones precisas y concretas a satisfacer por los poderes públicos" 14 .

12 M. S. Morón: Comentarios a las leyes Politicas. Constitución Española de 1978, Tomo ll, pág. 673.

13 LOEWENSTEIn. Ob. cit., pág. 241.

14 García Pelayo. El Estado de Partidos. Madrid, 1986, pág. 78. Añade Garcia PeLAYO a la capacidad de estructurar-racionalizar demandas sociales, la capacidad de crear esa misma demanda, ibid., págs. 78 y ss. 
Los partidos políticos son los instrumentos idóneos para la articulación del pluralismo político y de la participación.

Los textos constitucionales de la postguerra han reconocido esta función de los partidos; así la Ley Fundamental de Bonn en su artículo 21.1.1., les atribuye la misión de "cooperar(an) en la formación de la voluntad política del pueblo", en parecidos términos se expresa la Constitución francesa de 1958 (artículo 4), la Constitución italiana de 1947 (artículo 49).

En nuestro ordenamiento, al constitucionalizarse los partidos políticos se hace en términos parece que excluyentes:

"Los partidos políticos expresan el pluralismo politico, concurren a la formación de la voluntad popular y son instrumentos fundamentales para la participación política" (artículo 6) ${ }^{15}$.

“Los partidos políticos son en la Constitución española un medio para la participación política, pero no un medio cualquiera sino uno que se caracteriza por ser la base sobre la que aquélla se construye" 16 .

La realización de actos de propaganda electoral parecería, pues, en principio, limitada a estos grupos. No significa esto que se condene al silencio a los ciudadanos o a otros grupos distintos de los partidos; el ejercicio de la libertad de información y de la libertad de expresión, de opinión, no sufre un proceso de limitación en razón del desarrollo de una campaña electoral. El ejercicio normal de estos derechos puede, no hay duda, influir en el resultado del proceso electoral, pero ni son parte de la campaña electoral ni pueden suspenderse ni limitarse durante ésta.

Así lo entendia nuestro Tribunal Supremo en la Sentencia de 9 de diciembre de 1982, que confirmaba la Sentencia de la Audiencia Territorial de Sevilla de 15 de junio de $19822^{17}$. El fallo de la sentencia anuló un acuerdo de la Junta Electoral provincial de Sevilla de fecha 12 de mayo del mismo año por el que se denegó a la Confederación de Empresarios de Andalucía la posibilidad de realizar una "campaña de orientación de voto" en las elecciones autonómicas. La Audiencia de Sevilla alegó que

15 Nuestro Tribunal Constitucional se ha pronunciado ya en varias ocasiones sobre la función de los partidos políticos, asi STC 10/1983, de 21 de febrero, sobre el carácter no excluyente de la constitucionalización de los partidos políticos respecto de la participación. Vid. M. Ramirez: La participación política. Madrid, 1985, pág. 100.

16 GaAcla Ruiz: «Algunas reflexiones sobre la fórmula española de constitucionalización de los partidos políticos", RFDUC, 64, 1982, pág. 133.

${ }_{17}$ STS 9 de diciembre de 1982. Sala 5." (Ref Ar. 7542). 
la prohibición "viola o conculca el derecho fundamental de la recurrente (la Confederación) a la libertad de expresión".

Las libertades de la comunicación social en los períodos electorales "lejos de restringirse se amplian, puesto que este período de tiempo reviste unas características de confrontación ideológica y dialéctica que imponen una mayor permisibilidad en los usos del debate" ${ }^{18}$.

Tanto la Sentencia de la Audiencia Territorial de Sevilla como la del Tribunal Supremo, van a definir la campaña de orientación de voto como un conjunto de actividades tendentes a ofrecer al electorado "una determinada alternativa que influye o puede influir en desviar o llevar el voto del elector hacia los partidos que resulten afines con los intereses de quien realiza la actividad" (Audiencia Territorial de Sevilla), pero además «la captación de sufragios no se produce de modo inequívoco y en favor de una opción partidista en bloque" (Tribunal Supremo).

Entendemos que tras esta Sentencia parece abierto el camino para campañas paralelas de orientación de voto realizadas por las fuerzas sociales con peso específico, Iglesia Católica, Confederaciones empresariales, Centrales Sindicales... ${ }^{19}$. Si bien el acceso a los medios de comunicación en ejercicio del derecho de antena quedaría reservado a los partidos políticos.

\section{EL DERECHO DE ANTENA EN LA LEGISLACION ELECTORAL (1977-1982)}

La regulación de las campañas electorales está prácticamente ausente de nuestro derecho electoral, al menos de sus normas básicas, hasta la aprobación del Real Decreto-Ley 20/1977, de 18 de marzo, en plena transición política ${ }^{20}$.

Ya en su Exposición de Motivos, el Real Decreto 20/1977 hace referencia a la garantía de "la igualdad de todos los candidatos asegurada

\footnotetext{
18 S. Audiencia Territorial de Sevilla 15 de junio de 1982.

19 Sería ilusorio ignorar las campañas no institucionalizadas de orientación de voto realizadas por todas estas organizaciones.

${ }_{20}$ La primera regulación, de carácter limitativo, podemos fecharla en la II República a) prohibir una Orden de 7 de noviembre de 1933 la publicidad por radio de propaganda electoral. Por la Ley de Radiodifusión de 26 de junio de 1934 (art. 5) se autoriza la publicidad electoral y pública de carácter oneroso.

Aunque existen precedentes en la última etapa del franquismo sobre la regulación del uso, por los candidatos en las elecciones a Cortes por el tercio familiar de Procuradores, de medios de comunicación de titularidad pública, la especial naturaleza de estos procesos nos lleva a excluirlos del estudio.
} 
a través de los medios informativos de titularidad pública», para garantizar un voto libre.

El Título $V$ del Real Decreto-Ley regula específicamente el régimen de las campañas electorales, definiendo el contenido de éstas, así como su duración y las condiciones generales para la publicidad. El artículo 40 reconoce «el derecho al uso gratuito de espacios en la prensa, radio y televisión pública" a las asociaciones, federaciones, coaliciones y agrupaciones.

Se crea para el control de «la programación relacionada con las elecciones, de televisión y emisoras de radio de titularidad pública, durante la campaña electoral», un Comité para Radio y Televisión; este Comité realiza sus funciones bajo la dirección de la Junta Electoral Central.

En desarrollo del artículo 40 del Real Decreto-Ley 20/1977 se dictó el Real Decreto 967/1977, de 3 de mayo; este Real Decreto fijará los criterios para el acceso por parte de las distintas agrupaciones políticas.

Dos opciones son posibles, en abstracto, a la hora de fijar los criterios para la distribución de tiempos de programación entre las distintas fuerzas politicas.

La primera de ellas establece un principio de igualdad absoluta en el acceso, modulado tan sólo por la exigencia de presentación de candidaturas en un mínimo de circunscripciones electorales.

El segundo de ellos, aun reconociendo unos tiempos y espacios minimos, utiliza como criterio general para el reparto los resultados obtenidos por los partidos en anteriores procesos electorales, bien de forma exclusiva, bien en combinación con otros criterios (antigüedad del partido, número de afiliados, etc.) ${ }^{21}$.

Mientras en otros aspectos del régimen electoral, que nace con un afán de provisionalidad, las opciones que se le ofrecen al Gobierno eran, dentro de las previsiones de la Ley para la Reforma Política de 1977, diversas (sistemas de listas, número de diputados por distritos) no ocurría lo mismo respecto del acceso de los grupos políticos a los medios de comunicación de titularidad pública.

La segunda de las opciones no era posible desde el punto de vista fáctico, al ser las elecciones generales de 1977 las primeras a las que concurrían libremente partidos y agrupaciones, no existiendo por ello un referente inmediato que permitiera cuantificar el apoyo social de cada grupo político.

21 Sobre los principios que orientan el reparto de los tiempos de programación en el derecho electoral comparado, vid. Comentarios a la ley Orgánica del régimen electoral General. Madrid, 1986, dirigidos por L. Mena y Cazorla Prielo, págs. 577-580 y 586-590, también P. DEL CASTILLO: La financiación de los partidos y candidatos en las democracias occidentales. Madrid, 1985. 
Se establece, por tanto, un sistema de igualdad en la distribución de tiempos y espacios, así como en la participación en la Comisión para Radio y Televisión, el único criterio que introduce el Real Decreto 967/1977 para la atribución de estos espacios, será el número de las circunscripciones electorales en las que se presentan candidaturas ${ }^{22}$. Un procedimiento no excesivamente complejo, con la fijación de un número mínimo de distritos y la atribución en todo caso de tiempos y espacios en la programación regional (artículos 2 y 3 del real Decreto 967/1977). La determinación de los días y horas se realizará por la Dirección General de Radiodifusión y Televisión.

Por último, respecto del Comité para la Radio y Televisión, éste se integra por seis representantes del Gobierno y seis representantes nombrados por la Junta Electoral Central a propuesta de elos grupos y entidades" que presentan en las elecciones candidaturas en 25 o más distritos; se crean, además, Secciones de carácter territorial del Comité (artículo 6 R.D. 967/1977). Se prohíbe la contratación de espacios publicitarios en Televisión Española y Radio Nacional, no extendiéndose, sin embargo, la prohibición a las publicaciones periódicas integradas en ese momento en el Organismo Autónomo Medios de Comunicación Social del Estado, que también son objeto de una regulación específica en cuanto a condiciones para el acceso de los grupos políticos (art. 9 R.D. 967/1977).

La Ley 39/1978 de Elecciones Locales introducirá sólo ligeras modificaciones respecto del régimen previsto en el artículo 40 del Real Decreto-Ley 20/1977, y su normativa de desarrollo, normativa en la que se produce un reenvío en el párrafo $1 .^{\circ} \mathrm{del}$ artículo 20 . Tan sólo el párrafo $2 .^{\circ}$ de ese mismo artículo establece una garantía de presencia en el Comité de Radio y Televisión a favor de los Partidos, Federaciones y Coaliciones que hubiesen obtenido en las anteriores elecciones generales un número no inferior a cinco diputados.

Con posterioridad a la aprobación del texto constitucional, los procesos electorales se desarrollarán hasta la aprobación de la Ley Orgánica 5/1985, de 19 de junio, de acuerdo con el Real Decreto 20/1977, en las elecciones generales o bien en los procesos de ámbito local, de acuerdo con la Ley 39/1978.

La normativa que regula las elecciones generales de los años 1979 y 1982 presentan, desde nuestro punto de vista, serios problemas de constitucionalidad.

La CE establece en su artículo 81 una reserva a favor de la Ley

22 Una opinión en contrario mantiene RuIz NavarRo para quien "la regla general, hasta la ley Orgánica del Régimen Electoral General, ha sido distribuir los espacios gratuitos en los medios de comunicación social de titularidad pública en función de los votos obtenidos por cada partido en las anteriores elecciones, criterio que sin variación alguna ha adoptado la nueva ley" en Comentarios dirigidos por Cazorla Prieto, ob. cit., pág. 566. 
Orgánica sobre el régimen electoral general; la Disposición Transitoria $8 .^{a} 3$ del texto constitucional prorrogaba la vigencia de la normativa electoral preconstitucional "en caso de disolución de acuerdo con lo previsto en el artículo 115 , y si no se hubiera desarrollado legalmente lo previsto en los artículos 68 y 69 ". El fundamento de esta Disposición Transitoria $8 .^{a} 3$ no era otro que la dificultad de proceder a la aprobación inmediata de la nueva normativa electoral por unas Cortes que habian asumido unos poderes constituyentes y que podían ser disueltas en el plazo de un mes desde la promulgación de la Constitución.

La Disposición Transitoria $8 .^{\text {a }}$ no permitía al Gobierno modificar esa normativa integrada por el Real Decreto-Ley 20/1977 y sus normas de desarrollo, quedando asi congelado el régimen electoral general a la espera de la aprobación de la ley electoral; aprobación que debería producirse en la siguiente legislatura, pues la Disposición Transitoria $8 .^{a}$ agotaba su vigencia en la primera convocatoria de elecciones ${ }^{23}$.

Las Cortes Generales fueron disueltas y convocadas las elecciones por el Real Decreto 3073/1978, de 29 de diciembre. La aplicación de la normativa electoral anterior era plenamente constitucional, así, el R.D. 32/1979 convalida, entre otros, el R.D. 967/1977, sin embargo el R.D. 157/1979, de 2 de febrero, sobre "Normas aclaratorias del R.D. de 3 de mayo de 1977, sobre ejercicio del derecho al uso gratuito de espacios en televisión, radio y prensa «modifica sustancialmente las condiciones de acceso a estos medios de comunicación de titularidad pública. "La naturaleza meramente aclaratoria de la disposición últimamente citada era puramente semántica y formal; puesto que su exacto contenido implicaba una modificación y a la vez derogación de la normativa aclarada" 24 .

Las modificaciones afectaban fundamentalmente a tres cuestiones. En primer lugar, establecía unos requisitos más restrictivos para acceder a los espacios gratuitos de propaganda electoral; el R.D. 157/1979 exige para el acceso la presentación, por los partidos políticos, de candidaturas al Congreso y al Senado, manteniéndose el número mínimo de circunscripciones en el que deben presentarse candidaturas en 25 . La exigencia de que las candidaturas fueran presentadas por los partidos a ambas Cámaras, excedía de las facultades del Gobierno pero, además, vulneraba derechos adquiridos por las formaciones políticas conforme a la normativa anterior al dictarse el R.D. 157/1979, habiendo concluido ya el plazo de presentación de candidaturas ${ }^{25}$.

En segundo lugar, el R.D. 157/1979 establecía una preferencia

23 F. SANTAOLALla: “D. Tr. 8. ${ }^{a}$, en Comentarios a la Constitución, dirigidos por F. Garrido Falla, Madrid, 1980, pág. 1789.

24 M. BASSOLS COMA: "Las diversas manifestaciones de la potestad reglamentaria en la Constitución", RAP, núm. 88, 1979, pág. 139.

25 Para un análisis del conflicto vid P. DEL CASTILLO, Ob. cit., pág. 24. 
para la elección de los días y horarios de emisión de los programas, de acuerdo con su representación parlamentaria, modificando el principio de igualdad recogido en el R.D. 967/1977.

Por último, el R.D. 157/1979 redúce con carácter general la duración de los programas gratuitos de propaganda electoral.

La JEC entendió, por acuerdo de 5 de febrero de 1979, que la aplicación del R.D. 157/1979 vulneraría derechos adquiridos, entendiendo que la normativa aplicable era la contenida en el R.D. $967 / 1979{ }^{26}$.

En las elecciones convocadas por R.D. 2057/1982 de 7 de agosto, la situación era muy diferente; en principio la legislatura que terminaba su mandato deberia haber aprobado la nueva normativa electoral. Las Cámaras no aprobaron la Ley Orgánica correspondiente, sí aprobaron dos leyes que intentaban prorrogar, al menos parcialmente, la vigencia de la normativa preconstitucional. Así, la Ley Orgánica $2 / 1980^{27}$ de regulación de las distintas modalidades de referéndum se remite «En tanto no se promulgue la Ley Orgánica reguladora del régimen electoral general” al Real Decreto-Ley 20/1977, así como a "sus normas de desarrollo vigentes o que se aprueben con posterioridad" (Disposición Transitoria Primera de la L.O. $2 / 1980$ ); también la Ley $14 / 1980^{28}$ reguladora del régimen de encuestas electorales remite al Real Decreto-Ley 28/1977 (art. 10 de la Ley 14/1980).

Debemos entender, por lo tanto, que para el legislador no sólo continuaba vigente el Real Decreto-Ley 20/1977 sino que, además, era posible la modificación, por vía reglamentaria, de su normativa de desarrollo ${ }^{29}$.

El R.D. 2076/1982, de 27 de agosto, que desarrolla las normas complementarias para la celebración de las elecciones generales celebradas el 28 de octubre de ese año, modifica los criterios para la distribución de los espacios gratuitos de propaganda electoral, de acuerdo con el artículo 2. «El Comité de Prensa, Radio y Televisión, distribuirá, teniendo en cuenta criterios de proporcionalidad, los espacios gratuitos en la programación nacional de radio y televisión”. El principio de igualdad es sustituido por el de proporcionalidad sin que el R.D. determine su articulación exacta. ${ }^{30}$

El nuevo Comité de Prensa, Radio y Televisión es, en realidad, el anterior Comité de Radio y Televisión al que se le atribuyen unas facultades más amplias, incluyendo la determinación del reparto de espacios,

\footnotetext{
26 Vid. Bassols Coma, Ob. cit., pág. 137, y P. del Castillo, Ob. cit., pág. 243.

27 BOE, de 23 de enero de 1980.

28 BOE, de 25 de abril de 1980.

29 M. Bassols Coma, Ob. cit., pág. 137

En un sentido contrario a la tesis aquí sostenida, P. DEL CAstillo, Ob. cit.,
} pág. 250. 
así como competencias sobre la prensa pública en estos períodos electorales. Se establece un régimen más complejo para el nombramiento de vocales, así como igualmente una nueva categoría de éstos, los Vocales Técnicos, con voz pero sin voto, «nombrados por el Ministro de la Presidencia entre los profesionales de los medios de comunicación" (artículo 2. ${ }^{\circ}$ letra $c$ )

\section{LA LEY ORGANICA DE REGIMEN ELECTORAL GENERAL}

La importancia de la LOREG (L.O. 5/1985 de 19 de junio) no hace falta destacarla, da término a una situación de provisionalidad que se había prolongado más de lo constitucionalmente previsto.

La LOREG recogerá sustancialmente, en cuanto a los principios generales del derecho electoral, los contenidos del Decreto-Ley 20/1977 (circunscripción electoral, sistema proporcional de acuerdo con el método D'Hont (Congreso), sistema mayoritario para el Senado, etc.), no podía ser de otra forma desde que dichos principios se habian constitucionalizado en los artículos 68 y 69.

De acuerdo con una abundante jurisprudencia de nuestro Tribunal Constitucional, el contenido identificado como "régimen electoral general», objeto de reserva de ley orgánica de acuerdo con el artículo 81, abarca no sólo los procesos electorales generales (Congreso y Senado), sino que es necesario que contenga «por lo menos el núcleo central de la normativa atinente al proceso electoral, materia en la que se comprende lo relativo a quiénes pueden elegir, a quién se puede elegir y bajo qué condiciones, para qué espacio de tiempo y bajo qué criterios organizativos desde el punto de vista territorial y procedimental» ${ }^{31}$, al proceso electoral en su conjunto, siendo improcedente la pretendida «equiparación de las expresiones 'régimen electoral general' con 'elecciones generales'" 32 , por ello debemos entender que "El régimen electoral general está compuesto por las normas electorales válidas para la generalidad de las instituciones representativas del Estado en su conjunto y de las entidades territoriales en que se organiza, a tenor del artículo 137 de la Constitución española, salvo las excepciones que se hubiesen establecido en la Constitución o en los Estatutos" ${ }^{33}$.

Una definición tan amplia exige una norma reguladora, no sólo de una considerable extensión, sino también de un contenido variado, teniendo siempre como referente este proceso electoral. Así, algunos

\footnotetext{
31 STC 72/1984 de 14 de junio FJ 4.

STC 38/1983 de 16 de mayo FJ 2.

STC $38 / 1983$ de 16 de mayo FJ 3.
} 
autores han entendido que «la heterogeneidad es la característica fundamental del contenido de la 'nueva' normativa electoral» ${ }^{34}$.

El núcleo fundamental del régimen de las campañas electorales está contenido en el Capítulo VI del Titulo I (específicamente Secciones cuarta a sexta) buena parte de esa normativa de acuerdo con la Disposición Adicional 1. 2 se aplican también a las elecciones a Asambleas legislativas de las Comunidades Autónomas ${ }^{35}$.

El análisis de esta normativa referente a la regulación de las campañas electorales exige separar para su estudio la disciplina general de las campañas electorales, de la específica del acceso a los medios de titularidad pública y la publicidad en medios de titularidad privada.

\section{A) Campaña electoral: concepto y régimen jurídico}

El artículo 50.2 de la Ley, define la campaña electoral como «el conjunto de actividades lícitas, llevadas a cabo por los candidatos, partidos, federaciones, coaliciones o agrupaciones en orden a la captación de sufragios". De acuerdo con esta definición, tan sólo los partidos, agrupaciones, etc., están legitimados para el ejercicio de actividades tendentes a la captación de sufragios. El epígrafe 3 del mismo artículo 50 prohíbe expresamente la realización de campaña electoral a cualquier "persona jurídica distinta de las mencionadas en el apartado anterior", "a partir de la fecha de la convocatoria de las elecciones". No se entiende muy bien este último inciso, toda vez que cualquier acto anterior de orientación al voto no sería posible considerarlo como campaña electoral al no existir convocado proceso electoral alguno; en todo caso, la prohibición es relativa, toda vez que se reconoce que ésta se establece «sin perjuicio de lo establecido en el artículo 20 de la Constitución", ya hemos tenido oportunidad de referirnos a la inconstitucionalidad de cualquier limitación de las libertades de comunicación social en períodos electorales ${ }^{36}$.

Las actividades calificadas de campaña electoral son de distinto tipo y en conexión con el ejercicio de otros derechos fundamentales, asi, junto a la mención expresa en los artículos 50.3 y 53, el artículo 54 somete «la celebración de actos públicos de campaña electoral» a la legislación reguladora del derecho de reunión.

34 Alvarez Conde y Gonzalez Hernández, Código de Derecho Electoral Español. Prólogo. Madrid, 1985, pág. 39.

35 El Título para la reserva a favor del Estado en la materia tiene su fundamento en el artículo 149.1.1 que habilita al Estado para regular las condiciones básicas que garantizan la igualdad de todos los españoles en el ejercicio de los derechos constitucionales, en este caso artículo 23. Sobre la reserva a favor del Estado en el ámbito del 149.1.1., vid. J. L. Carro Fernández VAlmayor “Contenido y alcance de la competencia del Estado definida en el artículo 149.1.1 de la Constitución." REDC, n. ${ }^{\circ} 1$.

36 Vid. epígrafe 3. 
Por último, y en relación al régimen general de la campaña electoral, recordar la facultad reconocida en el artículo 50 a los poderes públicos para realizar campañas institucionales destinadas a «informar e incentivar la participación en las elecciones, sin influir en la orientación del voto de los electores».

Los fines de esta campaña pueden ser de distinta naturaleza, excluido el llamamiento en favor de una opción electoral, la campaña institucional puede bien informar sobre el ejercicio de los derechos electorales (por ejemplo, campañas informativas sobre el ejercicio del derecho de voto por correspondencia), o bien realizar un llamamiento a los electores para que participen en el proceso electoral. La utilización que se ha hecho de los medios de comunicación, especialmente de los de titularidad pública en estas campañas institucionales, ha sido en todas las ocasiones abundante, especialmente en los primeros años de transición.

B) El acceso de los partidos a los medios de titularidad pública y la disciplina de la propaganda en los medios de titularidad privada

Se establece una disciplina de la publicidad en medios de titularidad privada directamente, prohibiendo discriminación alguna a las distintas candidaturas «en cuanto a inclusión, tarifas y ubicación de los espacios de publicidad electoral» (artículo 58).

La publicidad, autorizada tanto en radio como en prensa de titularidad privada ${ }^{37}$, debe identificarse como tal (artículo 58.4) para garantizar la correcta información del elector.

Se establece, igualmente, una limitación indirecta al establecer un límite a los gastos electorales en el propio texto de la ley ${ }^{38}$.

En los medios de comunicación de titularidad pública se prohíbe expresamente la contratación de espacios de publicidad electoral; el principio que rige es el de la articulación de la propaganda electoral a través del ejercicio del derecho de antena, reconocido expresamente en el artículo 60 .

«Durante la campaña electoral, los partidos, federaciones, coaliciones y agrupaciones que concurran a las elecciones, tienen derecho a espacios gratuitos de

37 No todos los ordenamientos electorales permiten la utilización de medios de comunicación para la realización de campaña electoral cuando esta propaganda es pagada. Así, por ejemplo, el Código Electoral francés adjunto al D 64-1086 y D 64-1087 de 27 de octubre de 1984, prohibe la publicidad en prensa con fines de propaganda electoral, artículo L52-1 ( $\ln 661022$ de 29 de diciembre). y 193.2 .

Vid artículos 131130 b) de la Ley, y en relación con estos artículos 175.2 
propaganda en las emisoras de televisión y radio de titularidad pública, conforme a lo establecido en los artículos siguientes.”

La redacción es muy similar a la conocida del artículo 40 del RDL 20/1977, de 18 de marzo, con la desaparición de la mención a la prensa, lógica, al haberse procedido a la supresión de la prensa pública.

El artículo siguiente desarrolla los criterios para la distribución de los espacios gratuitos de propaganda electoral, fijándose como criterio general el número total de votos válidamente emitidos que obtuvo en cada circunscripción, según el ámbito de difusión del medio, cada formación política.

El número de votos obtenido en el anterior proceso electoral deberá combinarse con otros criterios, especialmente con la presentación de candidaturas en un mínimo de las circunscripciones electorales.

Para determinar tales resultados, a los efectos de la distribución de espacios gratuitos de propaganda electoral, se computan los votos obtenidos en la elección al Congreso de Diputados; la opción de combinar estos resultados con los del Senado, representaba dificultades para computar los datos, por ser las listas del Senado abiertas y producirse una cierta movilidad de votos.

Los criterios de distribución parten de un mínimun de circunscripciones electorales, que es del 75 por 100 del correspondiente a la difusión del medio, en el que tendrán que presentar candidaturas para poder participar en la programación correspondiente. Se supera así un límite que con carácter general se establecia en la normativa anterior, que era de 25 circunscripciones, si bien tal limitación (que en el ámbito nacional implica la presentación de candidaturas en 33 circunscripciones), se modula al establecerse un criterio individualizado en función a la difusión del medio. (Artículo 62 en relación con el 65.1.a) b) y c).)

Para los partidos que no hubieran concurrido anteriormente o no obtuvieran resultados superiores al 5 por 100 en el proceso electoral anterior, se conceden diez minutos en la programación del medio.

Aquellos partidos que hubieren obtenido en las anteriores elecciones entre un 10 y un 20 por 100 de los votos válidamente obtenidos en las anteriores elecciones, los tiempos son de veinte minutos.

Por último, para aquellos partidos que hubieren obtenido más de un 20 por 100 de los votos válidamente obtenidos en el anterior proceso electoral, dispondrán de treinta minutos.

Para permitir el acceso de los partidos nacionalistas a los medios de ámbito nacional se establece un mecanismo que permite otorgarles, 
tan sólo a aquellos que hubieren obtenido un 20 por 100 como mínimo de los votos válidamente emitidos, el mismo tiempo (30 minutos) que el previsto para los partidos (con los mismos resultados), de implantación nacional en estos medios, pero la difusión de estos programas será sólo en el ámbito de la Comunidad Autónoma.

El procedimiento es complejo, especialmente en lo referente a la programación de medios de ámbito local y a la de los medios de ámbito nacional en una difusión autonómica.

Sólo con la aplicación de la normativa por la JEC y las JEP en las elecciones de 22 de junio de 1986, hemos podido comprobar el funcionamiento real de los mecanismos de distribución previstos en la ley.

Adelantar, sin embargo, que estos criterios han permitido excluir de los programas en los medios nacionales o en los circuitos autonómicos, de partidos con importante implantación en determinadas Comunidades Autónomas, es el caso de ERC y EE; estos partidos, al no alcanzar el 20 por 100 de los votos obtenidos en la Comunidad Autónoma, sólo pueden acceder a la programación de medios cuyo ámbito de normal difusión sea la Comunidad Autónoma y en función de los resultados en cada una de las provincias (emisiones de RNE y RCE), así como a los medios de titularidad de la Comunidad Autónoma (TV 3 y TB) de acuerdo con los criterios del artículo 64. 1a), b) y c) en relación con el artículo 62.

\section{C) La neutralidad informativa de los medios de titularidad pública}

El principio de neutralidad en la actividad informativa de los medios de comunicación de titularidad pública es, en períodos electorales, esencial para el normal desarrollo de la campaña.

Los medios de comunicación de titularidad pública deben realizar una adecuada cobertura informativa de la campaña electoral, por ser, en primer lugar, parte de la vida política de la Comunidad, y en segundo lugar, para colaborar a la correcta formación de la opinión pública.

El mismo Estatuto de la Radio y la Televisión, Ley 4/1980, de 10 de enero, establece como primero de los principios inspiradores de la actividad de los medios de comunicación dependientes del Estado o de cualquier ente público.

«a) la objetividad, veracidad e imparcialidad de las informaciones" ${ }^{39}$.

39 Ley 4/1980, de 10 de enero, BOE núm. 12 de enero de 19870, artículo 4. 
En todo caso, los tiempos dedicados a la información sobre la campaña electoral no responden a los mismos criterios que el reparto de tiempos de emisión de propaganda electoral, y ello porque estos programas tienen una naturaleza informativa, y la determinación de su contenido y realización corresponde a empresas de gestión de los servicios de Radio y Televisión (RNE, RCE y TVE), bajo la dirección y control de los órganos que examinaremos inmediatamente.

Apuntar antes que ha desaparecido de nuestras campañas electorales esos programas falsamente informativos de las primeras elecciones, en los que bajo forma de información se daba lectura a comunicados de los distintos grupos políticos con un afán puramente propagandístico.

Naturalmente la actividad informativa no atinente a la campaña electoral, también deberá estar presidida por el principio de objetividad.

\section{D) Los órganos competentes}

Dos son los órganos competentes para la regulación de la campaña electoral a través de los medios de titularidad pública.

La Junta Electoral Central tiene atribuidas las competencias de control de los servicios en relación con la campaña (art. 66), así como las de distribución de los espacios gratuitos de propaganda electoral (art. 65 y 67).

La Comisión de Radio y Televisión actúa como órgano dependiente de la Junta Electoral Central.

El control de la Junta Electoral Central alcanza al desarrollo de la actividad informativa por parte de las sociedades de radio y televisión dependientes del Ente público de Radio y Televisión.

De acuerdo con el artículo 66 de la LOREG,

«las decisiones de los órganos de administración de los referidos medios en el indicado proceso electoral, son recurribles ante la Junta Electoral competente... y según el procedimiento que la Junta Central disponga».

En cuanto al procedimiento, señalar que la Junta Electoral Central aprobó en desarrollo de artículo 66, la Instrucción de 4 de noviembre de $1985^{40}$.

$40 B O E$, núm. 267 de 7 de noviemnbre, corrección de erratas $B O E$, núm. 272, de 13 de noviembre. 
Estas competencias de control con carácter general estaban ya previstas en el Estatuto de la Radio y la Televisión; de acuerdo con éste, la aplicación de la normativa electoral se realizaría por la Junta Electoral Central «que cumplirá su cometido a través del Consejo de Administración y del Director General’ ${ }^{41}$ de RTVE.

Respecto de la distribución de espacios gratuitos de propaganda electoral, ésta se realiza por la junta Electoral Central a propuesta de la Comisión para Radio y Televisión, propuesta que debemos entender no tiene carácter vinculante.

La Comisión para Radio y Televisión ha perdido la mayor parte de las competencias que anteriormente ostentaba. Pierde competencias de control de la programación que se le atribuirían en el R.D. 967/1977 (artículo 6.2), así como las facultades que para la distribución de los espacios gratuitos de propaganda electoral le atribuyó el R.D. 2076/82.

La Junta Electoral Central dirigía, en la normativa del año 1977, esta función de control de la Comisión (entonces Comité para Radio y Televisión) y conocía de los recursos, de acuerdo con el R.D. 2076/82, respecto de los acuerdos de la Comisión (entonces Comité de Prensa, Radio y Televisión" "42.

Se ha producido así una transformación del órgano, que, de órgano de ejecución y control, bajo la supervisión de la Junta Electoral Central, pasa a convertirse en un órgano de asesoramiento de éste con un único objeto: la distribución de los espacios gratuitos de propaganda electoral.

La estructura de la Comisión ha cambiado también profundamente. En su origen era un órgano paritario con representación de la Administración y grupos políticos en régimen de igualdad (R.D. 967/1977, art. 6.3), nombrados por la Junta Electoral Central, entre aquellos que concurren a las elecciones en un número mínimo de circunscripciones; la nueva regulación reserva el acceso a la Comisión a los partidos con representación en el Congreso, estableciéndose el voto ponderado de acuerdo con la composición de la Cámara.

El partido mayoritario se asegura asi el control de la Comisión para Radio y Televisión, desaparecen, además, los representantes de la Administración.

La Comisión en todo caso pasa a ser un órgano secundario, orientándose exclusivamente hacia una función de marco institucional de los acuerdos entre los partidos para el reparto de los tiempos de antena, función que ya desempeñaba antes.

41 Artículo 23 Ley 4/1980. Estatuto de la Radio y la Televisión.

42 Vid, artículos 6.2 del R.D. 967/1977, y artículo $2 .^{\circ} \mathrm{g}$ del R.D. 2076/82. 
La Junta Electoral Central, por el contrario, refuerza sus competencias, pasando a conocer directamente y con carácter ejecutivo de cuestiones que antes sólo conocía mediatamente o por vía de recurso.

Hemos señalado ya cuáles son estas funciones, apuntar ahora que parece una opción correcta, en aras de garantizar una mayor neutralidad del proceso electoral y de la actuación de los medios de comunicación. Debemos criticar, sin embargo, que las facultades de dirección y control de la programación general han quedado configuradas sólo como indirectas o por vía de recurso. Más adecuado hubiera sido que las competencias que el R.D. 967/1977 establecía a favor del Comité de Radio y Televisión, en materia de control de la programación, hubieran sido atribuidas a la Junta Electoral Central.

\section{LAS ELECCIONES DE 22 DE JUNIO DE 1986}

Llegamos así a las elecciones convocadas por el R.D. 794/1986, de 22 de abril. El proceso electoral de junio de 1986 ha estado enmarcado por una serie de circunstancias que han afectado directa $e$ indirectamente al desarrollo de la campaña electoral.

En primer lugar, destacar la desaparición de Unión de Centro Democrático que, pese a no haberse disuelto, no presentaba candidaturas en ninguna circunscripción; téngase en cuenta que en las elecciones de 28 de octubre de 1982, la UCD había obtenido, en número de votos válidamente emitidos, el tercer lugar tras el PSOE y CP.

La financiación de los partidos y coaliciones durante la campaña electoral, es otro punto a destacar del desarrollo de ésta. El acuerdo de la gran Banca de sindicar los créditos a los distintos partidos y establecer unos criterios uniformes, fue objeto de una gran polémica. Las críticas a la distribución efectuada de los créditos por entidades financieras señalaban, sobre todo, la posible beligerancia de la patronal bancaria al apoyar con grandes recursos financieros a una formación como el PRD, creado meses antes y con unas expectativas limitadas, como demostraban los sondeos y encuestas electorales, y vinieron a confirmar las urnas posteriormente, el apoyo contrastaba con la reducida financiación al CDS que, con mejores expectativas, entraba en competencia con el PRD por el espacio electoral que denominamos como centro progresista.

Al margen de todo esto, estudiemos la campaña electoral en los medios de comunicación.

Son éstas las primeras elecciones que nos permiten comprobar la aplicación de la normativa contenida en la LOREG, en la que nos inte- 
resa la regulación específica de los medios de comunicación durante la campaña electoral ${ }^{43}$.

\section{A) Comisión de Radio y Televisión}

La Comisión de Radio y Televisión, dependiente de la JEC, en cumplimiento del artículo 65 de la LOREG, queda integrada por representantes de IU, EE, CP, PSUC, PNV, PSOE, PSC-PSOE, C y U, CDS y ERC $^{44}$.

Contra el acuerdo de designación de los representantes en la Comisión de Radio y Televisión plantearon recursos la Mesa de Unidad de los Comunistas (MUC) y la de UCD, asi como otras formaciones políticas (estas últimas recurrieron, no la designación de los miembros de la Comisión estatal, sino la de los miembros de las Comisiones Provinciales designados por las Juntas Electorales provinciales).

La JEC resolvió, por Acuerdos de 19 de mayo y 2 de junio, desestimar dichas reclamaciones; concretamente en relación con la UCD, al no cumplir el primero de los requisitos del artículo 65.3 por no presentar candidatura en las elecciones, y en relación con la MUC por no cumplirse el requisito segundo, al no tener representación parlamentaria en el Congreso de los Diputados, pese a que candidatos de dicha formación eran miembros del Congreso de Diputados cuya legislatura terminaba, lo habían sido por otra formación política, en concreto el PCE, en estas elecciones integrante de la coalición electoral IU.

\section{B) La distribución de los espacios gratuitos de propaganda electoral}

La Comisión de Radio y Televisión elaboró una propuesta de distribución de espacios que fue asumida por la JEC en su comisión de 2 de junio ${ }^{45}$.

El contenido de la propuesta se resume en el cuadro siguiente:

43 Para una visión general de la aplicación de la normativa electoral en las elecciones de 22 de junio, véase la Crónica Electoral de E. ARnaldo AlcuBilla en este mismo volumen. Para el conocimiento de los textos de las resoluciones y acuerdos de la Junta Electoral Central (en adelante JEC) mencionadas en el estudio, nos remitimos desde ahora a dicha crónica.

44 La designación de la Comisión y de su Presidente y Vicepresidente por Acuerdo publicado en el BOE núm. 126 de 27 de mayo de 1986. La Presidencia de la Comisión recayó por sorteo en el representante de IU.

45 El País de 3 de junio. 


\section{TELEVISION ESPAÑOLA}

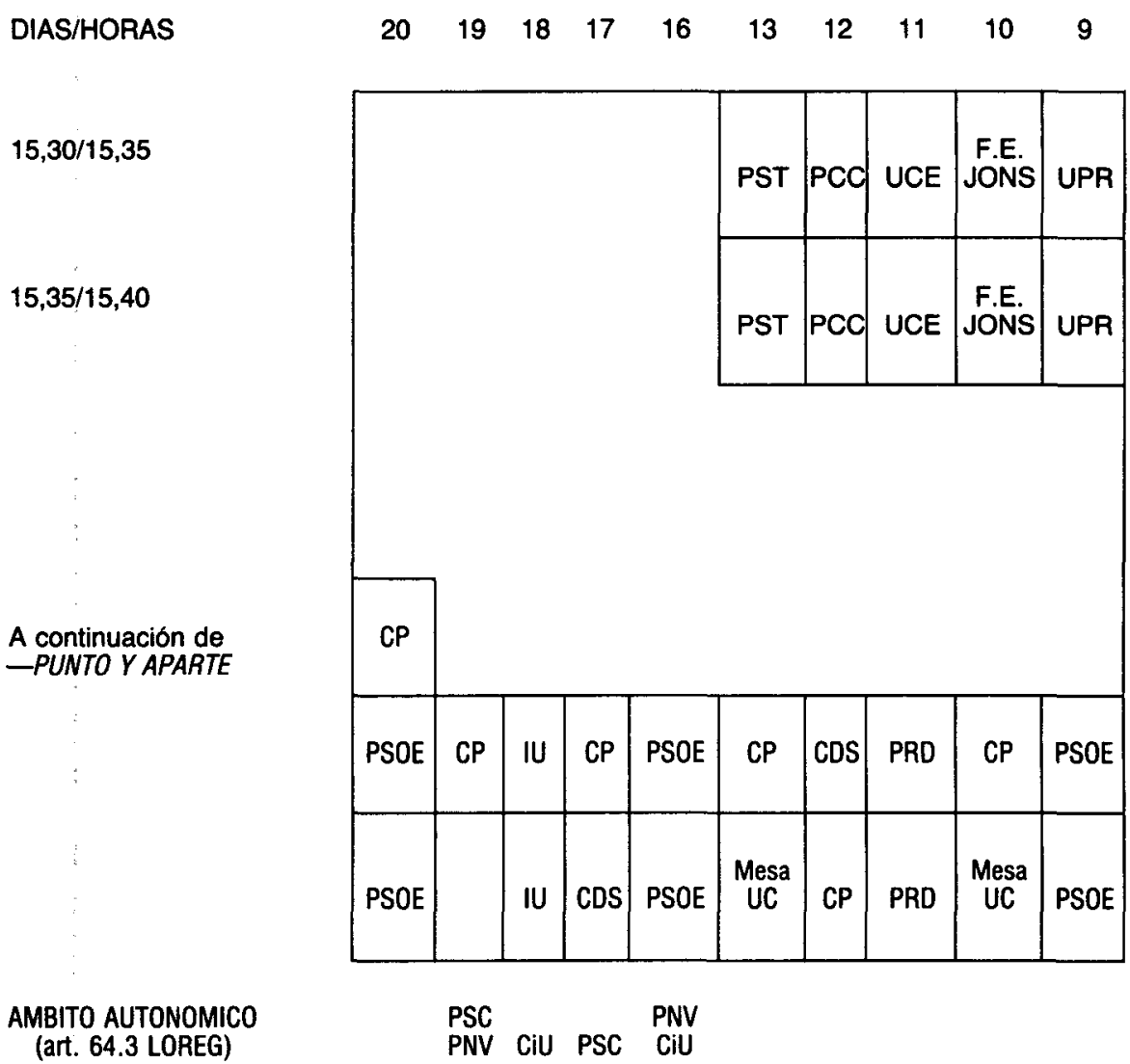




\section{RADIO NACIONAL DE ESPAÑA}

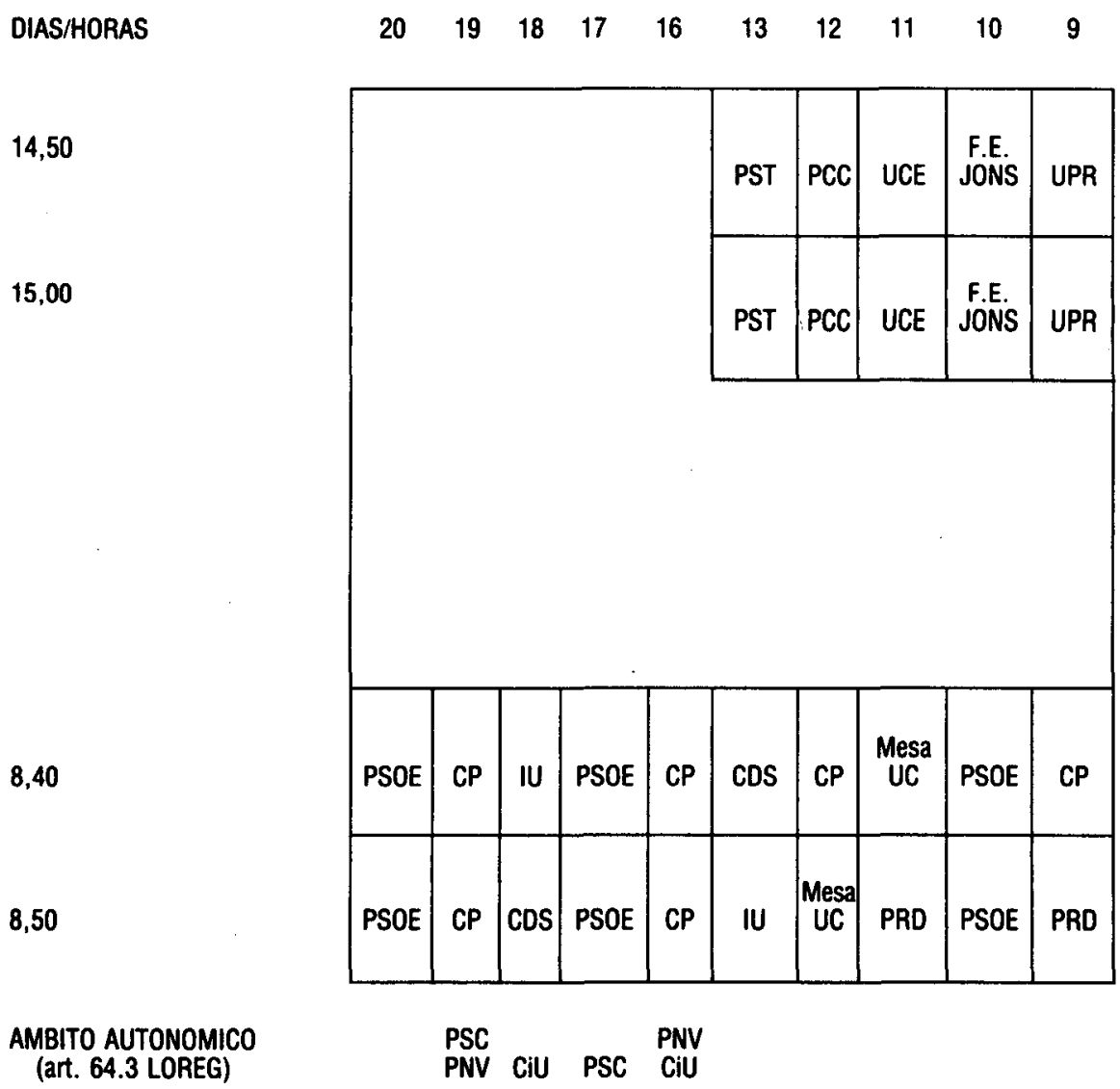


La distribución de espacios contenida en dicho acuerdo fue impugnada por diversas formaciones políticas.

Los recursos sobre esta distribución fueron desestimados por una serie de resoluciones de 9 de junio de 1986, entendiendo la JEC con carácter general que dicha distribución «respeta los criterios de proporcionalidad y preferencia establecidos en la Ley Electoral».

La distribución de los programas de ámbito nacional no representaba, en principio, excesivas dificultades ni críticas, quiza con la única excepción de la explícita marginación a la que se somete al PST, PCC, FE-JONS y UPR al señalarlas unos horarios de emisión de baja audiencia ${ }^{46}$. nómico.

No sucedió lo mismo con la programación de ámbito local y auto-

Respecto de la programación en el ámbito local se estimaron serios recursos de Unión Valenciana y el Partido Aragonés Regionalista que impugnaban acuerdos de las JEPs. de Valencia y Zaragoza, respectivamente. La JES estima su petición de espacios durante un total de 20 minutos tomando como fundamento el artículo 641 b) en relación con el inciso final del artículo 62.

Se desestimaron por el contrario recursos planteados por EE, ERC y Unio de l'Esquerra, que reclamaban el acceso a la programación en los circuitos de difusión regional de los medios nacionales, al no haber obtenido el 20 por 100 de los votos válidamente emitidos en la Comunidad Autónoma en las anteriores elecciones generales, requisito que establece el artículo 64.3 para el acceso a dicha programación.

Tan sólo el PNV, el PSC y CiU, pudieron acceder a estos programas de los servicios estatales pero con difusión autonómica al cumplir los requisitos antes señalados, de acuerdo con el cuadro de programación arriba reseñado.

\section{C) Pluralismo y neutralidad informativa de los medios de comunicación de titularidad pública}

El artículo 66 de la LOREG establece un principio de respeto a los principios de pluralismo y neutralidad de las que debe garantizarse por la organización de dichos medios.

46 El carácter fuertemente minoritario de estos grupos puede, en parte, justificar esta decisión. Conviene llamar la atención sobre el caso del PCC Partit dels Comunistes de Catalunya, que pese a tener una implantación exclusivamente de ámbito regional presenta candidaturas en circunscripciones electorales fuera de la Comunidad Autónoma catalana en un claro intento de conseguir espacios en la programación de ámbito nacional. La consecución de dichos espacios, en aplicación del art. 64.1 a) de la LOREG supone, en cierta medida, un fraude de ley. 
Los acuerdos del Consejo de Administración de RTVE del 12 de mayo de 1986, sobre cobertura informativa de la campaña electoral y sobre celebración de debates, trataban de cumplir las obligaciones impuestas por la LOREG.

Por el primero de estos acuerdos, la cobertura de la información de esta campaña no se realizará con el único criterio de la proporcionalidad para evitar la marginación de los grupos.

El reparto de los 284 minutos de programación informativa implicó, pues, una reducción significativa de tiempos informativos que deberían haber correspondido a la cobertura de la campaña del PSOE y CP.

La solicitud de varios partidos contrarios a la aplicación de este acuerdo y solicitando la aplicación de los criterios del artículo 64 de la LOREG, fue desestimada por la JEC, entendiendo que el criterio aplicable a los programas informativos era el artículo 66, como ya lo había hecho en su instrucción de 4 de noviembre de $1985^{47}$.

Por el segundo de estos acuerdos se decidió la realización, a petición de los partidos políticos, de una serie de programas de debate, realizándose un total de cuatro programas, dos de ellos entre el PSOE y CP, participando en el tercero PSOE-IU y Mesa UC y en el último, PSOECDS y PRD.

Señalar, por último, respecto del desarrollo de la campaña institucional, la importancia de los costes financieros de ésta, que ascendieron a 700 millones de pesetas, de los cuales 600 millones corresponden a los mensajes difundidos a través de TVE ${ }^{48}$.

\section{A) Actividades que no constituyen campaña electoral}

La realización de actos tendentes a pedir la abstención puede encontrarse amparada en el articulo 20 de la C.E., pese a que los partidos que la ejercitan no pueden realizar campaña electoral (Acuerdo de la JEC de 18 de junio de 1986).

\section{CONCLUSIONES}

1. La ordenación de las campañas electorales y, en concreto, de la utilización de los Medios de comunicación de titularidad pública parece

47 BOE, núm. 267 de 7 de noviembre.

48 El País, 29 de abril y 30 de mayo de 1986. 
una cuestión definitivamente resuelta en nuestro ordenamiento jurídico, no quiere decir esto que no sea susceptible de reforma, afirmamos que lo que no parece previsible es una desregularización de esta actividad.

2. La ordenación de las campañas electorales afecta fundamentalmente a los medios de titularidad pública, limitándose la disciplina de los medios de titularidad privada a la garantía del principio de no discriminación en la contratación de espacios publicitarios. Parece necesario proceder a una reforma del texto de la LOREG que garantice, al menos, unos mínimos de neutralidad de la prensa y de la radiotelevisión en manos privadas, especialmente cuando la regulación de televisión parece un hecho inminente en nuestro pais.

3. La ordenación de las campañas electorales en los medios de titularidad pública se articula en base a criterios distintos según la naturaleza de los espacios. Los espacios gratuitos de propaganda electoral se distribuyen de acuerdo con un principio general de proporcionalidad a los resultados electorales (votos válidos emitidos) en las anteriores elecciones.

Los espacios informativos de cobertura de la campaña electoral se organizan de acuerdo con el principio de pluralismo y neutralidad, no constituyendo actos de campaña, sino de información sobre ésta, no están sometidos al principio de proporcionalidad.

4. La ordenación de la distribución de espacios gratuitos de propaganda electoral en la LOREG (artículos 65 a 66) es compleja.

Se garantizan unos tiempos mínimos para aquellos partidos que presentan candidaturas en el 75 por 100 de las circunscripciones electorales comprendidas en el ámbito de difusión del medio, y que no concurrieron a las anteriores elecciones o no obtuvieron un mínimo del 5 por 100 de los votos válidos emitidos en las circunscripciones a las que alcanza la difusión del medio.

Los tiempos de programación se incrementan de acuerdo con los resultados (votos válidamente emitidos) en la anterior convocatoria electoral, de acuerdo con un baremo que clasifica en dos grupos a las formaciones políticas, aquellas que hubieren obtenido al menos un 5 por 100 de votos pero sin alcanzar el 20 por 100, y el segundo grupo, aquellas que hubieren obtenido por encima de este 20 por 100, adjudicándoles a estas últimas el tiempo máximo

En todos los casos, se exige como requisito haber presentado candidaturas al menos en un 75 por 100 de las circunscripciones comprendidas en el ámbito de difusión o programación del medio.

Se establece una regla excepcional que permite a los partidos que 
no hubiesen cubierto ese mínimo del 75 por 100 de candidaturas presentadas, siempre que hubieran obtenido al menos el 20 por 100 de los resultados en la Comunidad Autónoma, acceder a espacios en medios nacionales, si bien la emisión se circunscribe al ámbito de la Comunidad Autónoma.

La ordenación podría haberse simplificado desde el punto de vista puramente técnico. La garantía de unos mínimos atenúa los efectos de unos criterios tendentes a reforzar la concentración de la oferta política en pocos partidos y supone en último término un intento de articular un sistema bipartidista corregido con la presencia de partidos y coaliciones de implantación territorial limitada. 